Perspective Article

\title{
Chitosan/nanocellulose electrospun fibers with enhanced antibacterial and antifungal activity for wound dressing applications
}

\author{
Ana S. Ribeiro ${ }^{a}$, Sofia M. Costa ${ }^{a}$, Diana P. Ferreira ${ }^{a, *}$, Ricardo C. Calhelha ${ }^{\mathrm{b}}$, Lillian Barros ${ }^{\mathrm{b}}$, \\ Dejan Stojkovićc ${ }^{c}$, Marina Sokovićc ${ }^{c}$, Isabel C.F.R. Ferreira ${ }^{\mathrm{b}}$, Raul Fangueiro ${ }^{\mathrm{a}, \mathrm{d}}$ \\ ${ }^{a}$ Centre for Textile Science and Technology (2C2T), University of Minho, 4800-058 Guimarães, Portugal

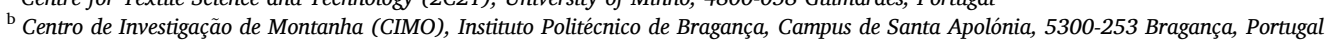 \\ ${ }^{\mathrm{c}}$ Institute for Biological Research "Siniša Stanković"- National Institute of Republic of Serbia, University of Belgrade, Bulevar despota Stefana 142, 11000 Belgrade, \\ Serbia \\ ${ }^{\mathrm{d}}$ Department of Mechanical Engineering, University of Minho, 4800-058 Guimarães, Portugal
}

\section{A R T I C L E I N F O}

\section{Keywords:}

Chitosan

Cellulose nanocrystals (CNC)

Electrospun nanofibers

Acacia natural extract

Drug delivery systems

\begin{abstract}
A B S T R A C T
The combination of biodegradable fibers at nanoscale with plant-based extracts is attracting increasing attention to produce wound dressing systems. In this work, nanofibers based on chitosan (CS), poly(ethylene oxide) (PEO), cellulose nanocrystals (CNC) and acacia plant-based extract were developed by electrospinning. Firstly, the polymeric formulations and electrospinning parameters were optimized, resulting in nanofibers with average diameters of $80 \mathrm{~nm}$. CNC were successfully introduced into the optimized CS/PEO blend and the membranes were characterized by FESEM, ATR-FTIR, TGA, XRD, WVTR and WCA. The CNC incorporation improved the nanofibers' physical integrity, morphology, diameters, water vapor transmission rate and thermal properties. After acacia introduction into the best CS/PEO/CNC system, the antibacterial effect was relatively maintained while the antifungal activity was enhanced for some fungi, demonstrating its great effect against a wide range of microorganisms, which is crucial to prevent or treat infections. All the developed systems exhibited absence of cytotoxicity in non-tumor cells, suggesting their biocompatibility. Finally, a continuous release of the acacia extract was observed for $24 \mathrm{~h}$, showing its prolonged action, which contributes to the healing process while reduces the frequency of dressing's replacement. Overall, the developed nanofibers are very promising to act as localized drug delivery systems for wound care applications.
\end{abstract}

\section{Introduction}

Skin wounds are an important healthcare problem associated with significant morbidity and mortality rates. Despite the progress in wound dressing systems over the last years, the limited effectiveness of the currently available treatments is still a challenge. Therefore, the exploration of innovative approaches for the development of new systems with improved performance in accelerating wound healing and skin regeneration is essential $[1,2]$.

In recent years, electrospinning has gained tremendous interest by the scientific community to produce wound dressings. Besides the technique's simplicity of use, versatility and scalability, the generated electrospun nanofiber's mats present excellent properties, such as high surface-to-volume ratio, high porosity, flexibility and absorption of wound exudate. Due to their nanoscale features, these membranes are capable of mimic the extracellular matrix (ECM) structure, promoting the regeneration of the injured skin by favoring the cells' attachment, proliferation and migration. Additionally, the highly interconnected pore structure with reduced pore size not only prevents microbial penetration avoiding the development of infections, but also allows water and oxygen permeability. Furthermore, the possibility to incorporate bioactive molecules with an active role in the healing process while ensuring their sustained release to the wound site shows the promising potential of these membranes to act as advanced biologically active dressings. All these properties are determinant for an effective wound healing process [2-5].

\footnotetext{
* Corresponding author.

E-mail addresses: anaribeiro@fibrenamics.com (A.S. Ribeiro), sofiamcosta@det.uminho.pt (S.M. Costa), diana.ferreira@det.uminho.pt (D.P. Ferreira), calhelha@

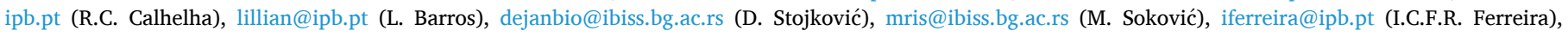
rfangueiro@dem.uminho.pt (R. Fangueiro).
} 
Nowadays, the great demand for sustainable alternatives in wound care industry makes natural-based and biodegradable materials suitable candidates for the development of environmentally friendly wound dressings. Chitosan (CS) is a natural biopolymer derived from the chitin deacetylation, found on crustacean's shells (e.g. shrimps, lobsters and crabs), fungi, algae cell walls, etc. This natural polysaccharide has attracted much attention in numerous biomedical applications because of its well-known exceptional biocompatibility, non-toxicity, antimicrobial activity against a wide range of bacteria and fungi, nonimmunogenicity and readily biodegradability [6-8]. Nevertheless, the production of neat CS nanofibers is a challenge mainly because of its rigid chemical structure, polycationic nature and specific inter and intramolecular hydrogen bond interactions. To overcome these problems, a co-spinning agent must be added to CS solution to improve its electrospinnability, such as poly(ethylene oxide) (PEO), which is also biodegradable, biocompatible and non-toxic [8-10]. Cellulose nanocrystals (CNC) have been widely used as a reinforcing material to improve nanofibers' mechanical and thermal properties. Additionally, CNC have also been known to enhance nanofibers' morphology and to favorably influence the nanofibers diameters to lower values [11]. Besides their nanometric size, large surface area and high strength, these nanocrystals are also biodegradable and derived from renewable sources, allowing the production of bio-based nanofibers with improved performance [10].

Infections are a major issue in wound healing process. In fact, the growth of microorganisms and the formation of biofilms in the wound surface compromise the healing process. Hence, wound dressings must contain antimicrobial agents in order to prevent or treat infections [4]. In recent years, the search for antimicrobial agents derived from natural sources has gained great attention because of their therapeutic properties, cost-effectiveness, low adverse effects and due to the increase of multidrug resistant bacteria as a consequence of the continuous administration of antibiotics. Furthermore, the incorporation of natural compounds into nanofibers allows a continuous local delivery of the antimicrobial agents, enhancing the healing process [12,13]. Acacia tortilis is a medical specie of genus Acacia that belongs to the Leguminoase family. Acacia contains a lot of medicinal properties such as antimicrobial, anti-inflammatory and antioxidant, which are essential for several biomedical applications [14,15]. Although acacia antimicrobial activity has already been studied [16], as far as the authors know, its effect when incorporated into nanofibers has never been reported. Therefore, the introduction of this plant-based extract will possibly increase the antibacterial and antifungal effect of these biobased nanofibers, providing a synergetic effect for wound healing process and regeneration of the lost tissue.

By the combination of natural-based and biodegradable compounds, $\mathrm{CS} / \mathrm{PEO} / \mathrm{CNC} /$ Acacia, it's possible to merge the properties of each material to create a new fibrous system not only with higher performance but also to be used as a green alternative for wound care applications.

In this way, the purpose of this work is the development of active drug delivery systems for wound dressing applications based on electrospun biodegradable nanofibers with CS and PEO biopolymers reinforced with CNC. Firstly, nanofibers production was optimized and the effect of different CNC concentrations $(0.1,0.5,1$ and $2 \%(w / v))$ and acacia natural extract introduction was investigated. Electrospun nanofibers were characterized by Field Emission Scanning Electron Microscopy (FESEM), Attenuated Total Reflectance-Fourier Transform Infrared Spectroscopy (ATR-FTIR), Thermogravimetric Analysis (TGA), X-Ray Diffraction (XRD), Water Vapor Transmission Rate (WVTR) and Water Contact Angle (WCA) techniques. Additionally, their antibacterial activity against Gram-positive and Gram-negative bacteria was explored as well as antifungal effect against six different fungi. The cytotoxicity was also assessed using non-tumor pig liver cells. Finally, UltravioletVisible (UV-Vis) spectroscopy was used to assess the release profile of acacia from nanofibers' membranes. Overall, this work reports, for the first time, the development of antimicrobial and biocompatible electrospun nanofibers based on $\mathrm{CS} / \mathrm{PEO} / \mathrm{CNC} / \mathrm{Acacia}$ with great potential for wound care.

\section{Experimental}

\subsection{Materials}

CS (high molecular weight, 310,000-375,000 Da) and PEO (molecular weight $900 \mathrm{kDa}$ ) powders were purchased from Sigma-Aldrich as well as Dimethyl Sulfoxide (DMSO) anhydrous $\geq 99.9$. CNC were provided by CelluForce (CelluForce NCC ${ }^{\circledR}$ - spray-dried powder form). Glacial acetic acid $99-100 \%$ a.r. was purchased from Normax. Acacia tortilis (Forssk.) Hayne ssp. raddiana fresh leaves (5 to 10 different plants) were collected from the extreme south of the Algerian Saharan desert in the Tamanrasset region (Coordinates: $22^{\circ} 47^{\prime} 13^{\prime \prime} \mathrm{N}, 5^{\circ} 31^{\prime} 38^{\prime \prime} \mathrm{E}$ ) in September of 2017, subsequently, they were shade dried, ground to a fine powder and extracted by maceration using ethanol/water (80:20, $v$ / v), following a previously described procedure using the same plant species [16]. The extract was further characterized regarding the phenolic composition using an UPLC Dionex Ultimate 3000 (Thermo Finnigan, San Jose, CA, USA) equipped with a DAD, measuring at 280, 330 and $370 \mathrm{~nm}$, and a Linear Ion Trap LTQ XL mass spectrometer (Thermo Finnigan), working in negative ion mode [16].

\subsection{Preparation CS/PEO blends incorporated with CNC and natural extract (acacia)}

Defect-free nanofibers were obtained thought the optimization of several CS/PEO solution parameters, namely CS/PEO concentration, solvent system concentration, CS pre-processing and blend solution postprocessing (data not shown). Briefly, CS/PEO solutions with a weight ratio of $1: 1$ and a total polymer concentration of $2 \%(w / v)$ were prepared in $50 \%(v / v)$ acetic acid aqueous solution. The polymeric solution was homogenized (using a X 1000D homogenizer (CAT) during $5 \mathrm{~min}$ at $23300 \mathrm{rpm}$ ) and centrifuged for $30 \mathrm{~min}$ at $5000 \mathrm{rpm}$ to remove the suspended particles and the air bubbles. Subsequently, different CNC concentrations $(0.1,0.5,1$ and $2 \%(\mathrm{w} / \mathrm{v}))$ were added to the polymeric solution. The addition of CNC powders was gently to avoid CNC clusters formation and the polymer blend was left overnight under vigorous stirring for a total homogenization. Finally, acacia natural extract was dissolved in a minimal amount of DMSO and introduced in CS/PEO/ $\mathrm{CNC}$ formulation with a final concentration of $6 \mathrm{mg} / \mathrm{mL}$.

\subsection{Properties of the solution - Viscosity and conductivity}

The viscosity and electrical conductivity of the developed solutions were measured ( 3 times) using a rotary viscometer serie VB 3000 and a TDS 4510 conductivity meter, respectively. A spindle R5 with $60 \mathrm{rpm}$ of velocity was used for the viscosity.

\subsection{Electrospinning process}

All the solutions were electrospun in an electrospinning NF-103 equipment from MECC. The optimized equipment conditions that allowed the formation of a stable jet and the production of defect-free nanofibers are described in Table 1.

\subsection{Nanofibers characterization}

\subsubsection{FESEM}

The nanofibers' morphology and diameter were evaluated using Ultra-high-resolution FESEM, NOVA 200 Nano SEM, FEI Company (Hillsboro, OR, USA). The membranes were removed from the aluminium foil and coated with a very thin film $(20 \mathrm{~nm})$ of $\mathrm{Au}-\mathrm{Pd}$ (80-20 wt\%), using a high-resolution sputter coater, 208 HR Cressington Company (Watford, UK), coupled to a MTM-20 Cressington High 
Table 1

Optimized electrospinning conditions to produce CS/PEO/CNC nanofibers.

\begin{tabular}{ll}
\hline Parameters & Optimized values \\
\hline Voltage & $29 \mathrm{kV}$ \\
Flow rate & $4 \mathrm{~mL} / \mathrm{h}$ \\
Tip-collector distance & $170 \mathrm{~mm}$ \\
Needle diameter & $0.41 \mathrm{~mm}$ \\
Volume & $12 \mathrm{~mL}$ \\
Deposition time & $6 \mathrm{~h}$ \\
Cleaning Frequency & $90 \mathrm{~s}$ \\
Head Transverse speed & $50 \mathrm{~mm} / \mathrm{s}$ \\
Head Transverse Distance & $150 \mathrm{~mm}$ \\
Type of collector & Rotary \\
Speed Rotation & $100 \mathrm{rpm}$ \\
\hline
\end{tabular}

Resolution Thickness Controller. Secondary electron images, i.e., topographic images, were performed at acceleration voltage of $10 \mathrm{kV}$.

\subsubsection{Nanofibers diameters}

The diameters of the fibers were determined using Image $\mathrm{J}$ software. The images of each sample were analysed, and the diameters were measured in 100 different locations.

\subsubsection{ATR-FTIR}

Chemical composition of nanofibers was evaluated by ATR-FTIR analysis (in different sites to ensure homogeneity) with an IRAffinity1S, SHIMADZU equipment (Kyoto, Japan). Each spectrum was acquired in transmittance mode using diamond ATR crystal cell by accumulation of 45 scans with a resolution of $8 \mathrm{~cm}^{-1}$ and recorded over a wavenumber range of 400 to $4000 \mathrm{~cm}^{-1}$.

\subsection{4. $T G A$}

Thermal stability of the developed nanofibers was evaluated by TGA. This analysis was performed on a STA 700 SCANSCI, under nitrogen atmosphere, in the range of $30-600{ }^{\circ} \mathrm{C}$ with a constant heating rate of $10{ }^{\circ} \mathrm{C} / \mathrm{min}$.

\subsection{5. $X R D$}

Crystalline structure of nanofibers was evaluated using a Bruker D8 Discover diffractometer, operated at a voltage of $40 \mathrm{kV}$ and a current of $40 \mathrm{~mA}$ with $\mathrm{Cu}-\mathrm{K}_{\beta}$ radiation. Data were collected for $2 \theta$ values ranging from $5^{\circ}$ to $35^{\circ}$.

\subsubsection{WVTR}

The WVTR was obtained based on the standard BS 7209:1990, with slight modifications and using 6 replicates. Test heads containing $46 \mathrm{~mL}$ of distilled water were totally covered with a nanofiber membrane and placed in a water vapor permeability tester TF156 (TESTEX) with controlled $\left(20^{\circ} \mathrm{C} \pm 2{ }^{\circ} \mathrm{C}\right)$ and humidity $(65 \% \mathrm{RH} \pm 2 \%)$. The test heads were weighted after $24 \mathrm{~h}$ for monitoring the weight loss. The WVTR was calculated over $24 \mathrm{~h}$, accordingly with Eq. (1).

$\mathrm{WVTR}=24 \mathrm{M} / \mathrm{At}$

where $M$ represents the weight loss in the sample, $t$ is the elapsed time and $\mathrm{A}$ is the cross-sectional area of the nanofiber membrane.

\subsubsection{WCA}

The hydrophilic character of the developed membranes was evaluated (in ten different sites of the sample) using a Contact Angle System OCA 15 (dataphysics) attached to a high-resolution camera. A volume of $5 \mu \mathrm{L}$ distilled water was deposited on the samples and the contact angle was measured through the drop shape analysis.

\subsection{Nanofibers properties evaluation}

\subsubsection{Antibacterial activity}

Antibacterial activity of the nanofibers was tested against six bacteria species: Gram-positive Bacillus cereus (clinical isolate), Listeria monocytogenes (NCTC 7973), and Staphylococcus aureus (ATCC 6538) bacteria as well as Gram-negative Enterobacter cloacae (clinical isolate), Escherichia coli (ATCC 35218), and Salmonella Typhimurium (ATCC 13311). This assay was performed by microdilution method (Clinical and Laboratory Standards Institute) utilizing 96-well microtiter plates to determine the minimum inhibitory concentration (MIC) and minimum bactericidal concentration (MBC), following a procedure previously described $[17,18]$. The extracts were dissolved in $30 \%$ methanol and added to Tryptic Soya Broth (TSB) medium and after inoculated with bacteria in a final concentration $1 \times 10^{6} \mathrm{CFU} /$ well. The lowest concentration that produced a significant inhibition (around 50\%) of the growth of the bacteria in comparison with the positive control was identified as the MIC, while MBC was obtained by the lowest concentration that showed no growth after sub-culturing of treated bacteria. The results were expressed in $\mathrm{mg} / \mathrm{mL}$ and ampicillin (Panfarma, Belgrade, Serbia) was utilized as positive control $(1 \mathrm{mg} / \mathrm{mL}$ in sterile saline solution) and $30 \%$ methanol was used as negative control.

\subsubsection{Antifungal activity}

Antifungal activity of the membranes was tested against six fungi: Aspergillus fumigatus (ATCC 1022), Aspergillus niger (ATCC 6275), Aspergillus versicolor (ATCC 11730), Penicillium funiculosum (ATCC 8725), Penicillium aurantiogriseum (food isolate), and Trichoderma viride (IAM 5061). A microdilution technique was also applied to determine the antifungal activity following a procedure previously described by the authors [19,20]. Minimum inhibitory concentration (MIC) was determined by serial dilution technique using 96-well microtiter plates. While, the minimum fungicidal concentration (MFC) was determined by the lowest concentration without visible biomass growth indicating the death of $99.5 \%$ of the original inoculum. The commercial fungicide ketoconazole was used as positive control. Methanol $(30 \%(v / \mathrm{v}))$ was used as the negative control.

\subsubsection{Cytotoxic activity}

For the evaluation of the nanofibers' cytotoxic activity the Sulforodamine B (SRB) assay was performed on a non-tumor primary cell line (PLP2) following a methodology previously described [21]. The membranes were tested in concentrations of 8 to $0.125 \mathrm{mg} / \mathrm{mL}$ diluted in water and as a positive control, ellipticine was used. Dose-response curves were obtained and the $\mathrm{GI}_{50}$ values, corresponding to the concentration of extract that inhibited $50 \%$ of cell growth, were calculated [22].

\subsubsection{Acacia release profile}

Acacia release profile from nanofibers was monitored over $24 \mathrm{~h}$ by UV-Vis spectroscopy using a Shimadzu UV-1800 spectrophotometer. Firstly, pseudo-extracellular fluid (PECF) formulation was prepared in order to mimic the wound fluids, accordingly with [23,24]. Afterwards, a section of each membrane $\left(1 \times 1.5 \mathrm{~cm}^{2}\right)$ was immersed in PECF solution ( $3 \mathrm{~mL}$ ) with $\mathrm{pH}$ of $8 \pm 0.5$, and the samples were put in an orbital Shaker Ivymen at $37{ }^{\circ} \mathrm{C}$ and $30 \mathrm{rpm}$. At different time points $(0,5,15$, $30,45 \mathrm{~min}, 1,2,5,7$ and $24 \mathrm{~h}$ ), an aliquot was removed and evaluated by UV-Vis at wavelengths between 230 and $500 \mathrm{~nm}$ (3 replicates).

\section{Results and discussion}

\subsection{Composition of acacia extracts and nanofibers production optimization}

According to a previous work [16], the hydroethanolic extract of acacia revealed the presence of thirty-six compounds, being composed 
of galloylquinic derivatives, gallic acid esterified derivatives, flavan-3ols galloyl derivatives ((epi)gallocatechin-gallate (EGCG) O-acyl derivatives) and a flavonol, which were previously described in two types of extracts (decoctions and ethanol extracts). Trigallic acids were the most abundant compounds, as also found in the hydroethanol extract used in this study [16]. After the careful optimization of the electrospinning formulations composed by CS and PEO, CNC nanofillers were introduced in the optimized polymer blend solution in order to improve the thermal properties of the electrospun CS/PEO nanofibers, as well as their electrospinnability and morphology. Several CNC concentrations were evaluated from 0.1 to $2 \%(w / v)$. The viscosity and conductivity values of the different solutions were measured, and the results are represented in Table 2.

As it can be observed in Table 2, the CNC incorporation led to an increase of the CS/PEO polymeric solution's viscosity values. This result can be due to the increase of the number of hydrogen bonding interactions between CNC and polymeric matrix already reported in a previous study [25]. The conductivity values also increased with the addition of CNC, being this increase proportional to CNC concentration. This finding can be due to the negative charges from the sulfate ester groups present on CNC surface, which contribute to the increase of solution charge density, thereby increasing the solution's conductivity $[10,26,27]$. The morphology and diameters of the CS/PEO nanofibers containing different CNC concentrations were evaluated by FESEM analysis, as demonstrated in Fig. 1.

The incorporation of CNC into CS/PEO blend not only improved the solution's electrospinnability but also promoted a slightly reduction in the average diameters of nanofibers from 80 to $65,70,74$ and $79 \mathrm{~nm}$, accordingly with CNC concentration (from 0.1 to $2 \%$ ). Furthermore, a more uniformed diameter distribution was observed with $1 \%(w / v) \mathrm{CNC}$, because the range of nanofibers' diameter distribution was lower and more concentrated between 53 and $80 \mathrm{~nm}$ (histogram from Fig. 1D). Nevertheless, with lower amounts of CNC visible beads were still observed (Fig. 1B and C), while with higher CNC concentrations these beads tended to disappear (Fig. 1D and E). The reduction of the defects in nanofibers when the amount of CNC is increased can be related to the higher values of conductivity (Table 2), which favors the formation of more uniform fibers due to the larger stretch of the jet. Other possible explanation is related to the interactions between CNC and polymeric chains, which increases the entanglement of the polymer chains, thereby preventing the jet from breaking during the electrospinning process, and consequently, decreasing the defects [10]. These results were also confirmed by the images of the final membranes (Fig. 1F and G), where it's clearly visible that the electrospun membranes produced with $\mathrm{CNC}$ showed less defects in its structure and became more resistant and less brittle, being these features very important for skin applications.

\subsection{Chemical, thermal and crystalline properties}

In order to evaluate the interaction between the polymers, thermal stability and crystalline structure, ATR-FTIR, TGA and XRD techniques were performed, respectively. The results are displayed in Fig. 2.

The main characteristic bands peaks of CS, PEO and CNC powders are displayed in Fig. $2 \mathrm{~A}$ and B. In fact, CS spectrum presents a broad band located at $3360 \mathrm{~cm}^{-1}$ that can be attributed to $\mathrm{O}-\mathrm{H}$ and $\mathrm{N}-\mathrm{H}$

\section{Table 2}

Viscosity and conductivity values of the different CS/PEO formulations with CNC.

\begin{tabular}{lll}
\hline Polymeric formulations & Viscosity $(\mathrm{mPa})$ & Conductivity $(\mu S)$ \\
\hline CS/PEO & 3500 & 65.1 \\
CS/PEO/0.1\% CNC & 3580 & 69.1 \\
CS/PEO/0.5\% CNC & 3650 & 69.4 \\
CS/PEO/1\% CNC & 3660 & 76.7 \\
CS/PEO/2\% CNC & 4490 & 98.7 \\
\hline
\end{tabular}

stretching vibrations. Moreover, the bands at 1651 and $1555 \mathrm{~cm}^{-1}$ are from amide $\mathrm{I}(\mathrm{C}=\mathrm{O}$ stretching) and $\mathrm{II}(\mathrm{N}-\mathrm{H}$ bending), respectively. Finally, the bands at 1150, 1057, 1026 and $895 \mathrm{~cm}^{-1}$ are from CS saccharide region $[10,23]$. In PEO spectrum, the band at $2878 \mathrm{~cm}^{-1}$ is attributed to $\mathrm{C}-\mathrm{H}$ bonds and the bands at 1146,1092 and $1061 \mathrm{~cm}^{-1}$ as triplet peaks are from C-O-C stretching vibrations [28]. ATR-FTIR spectrum of CNC powder revealed the presence of bands located at 3333 and $2897 \mathrm{~cm}^{-1}$ that correspond to $\mathrm{O}-\mathrm{H}$ and $\mathrm{C}-\mathrm{H}$ stretching vibrations, respectively. The band at $1427 \mathrm{~cm}^{-1}$ is attributed to the bending vibrations of $\mathrm{CH}_{2}$ and the one at $1315 \mathrm{~cm}^{-1}$ is from bending vibrations of the $\mathrm{C}-\mathrm{H}$ and $\mathrm{C}-\mathrm{O}$ groups of the rings in polysaccharides. Finally, the bands observed in the range $1030-1161 \mathrm{~cm}^{-1}$ correspond to $\mathrm{C}-\mathrm{O}$ stretching and $\mathrm{C}-\mathrm{H}$ rocking vibrations of the saccharide structure $[10,29]$. Regarding CS/PEO nanofibers, it was visible the characteristics bands of both polymers, confirming the interaction between CS and PEO. The introduction of CNC led to the appearance of CNC specific bands including at 1420,1315, 1204 and $1030 \mathrm{~cm}^{-1}$, confirming the successful incorporation of CNC into CS/PEO nanofibers. Furthermore, the band located at $3360 \mathrm{~cm}^{-1}$ in the CS/PEO nanofibers spectrum shifted to smaller wavenumbers $\left(3345 \mathrm{~cm}^{-1}\right)$ and increased in intensity with CNC addition, suggesting an interaction between $\mathrm{OH}$ groups from CNC and ammonium groups from CS by hydrogen bonds [10,30].

The thermal decomposition behaviour of nanofibers containing different CNC concentrations is demonstrated in Fig. 2C and D. TGA curve of CS/PEO nanofibers (Fig. 2C) clearly showed two main mass loss steps: the first one $\left(200-350{ }^{\circ} \mathrm{C}\right)$ corresponds to CS degradation, while the second one $\left(350-450{ }^{\circ} \mathrm{C}\right)$ is related with PEO decomposition, with weight losses of $33 \%$ and 54\%, respectively. DTG analysis (Fig. 2D) demonstrated that the maximum degradation peak of CS and PEO occurred at $275{ }^{\circ} \mathrm{C}$ and $393{ }^{\circ} \mathrm{C}$, respectively [10,31]. The addition of different $\mathrm{CNC}$ concentrations $(0.1,0.5,1$ and $2 \%$ ) revealed the appearance of new peaks at $334,334,342$ and $353{ }^{\circ} \mathrm{C}$, respectively, which corresponds to CNC degradation. Moreover, the CNC incorporation into nanofibers promoted a shift of the CS and PEO maximum degradation peaks to higher temperatures. For instance, CS/PEO/2\% CNC nanofibers demonstrated an increase from $275^{\circ} \mathrm{C}$ to $281^{\circ} \mathrm{C}$ for CS and from $393{ }^{\circ} \mathrm{C}$ to $396^{\circ} \mathrm{C}$ for PEO, which corresponds to an increase of maximum degradation temperature of $6{ }^{\circ} \mathrm{C}$ and $3{ }^{\circ} \mathrm{C}$, respectively. Hence, these results showed that CNC incorporation slightly improved the thermal stability of CS/PEO nanofibers.

In Fig. 2E, XRD spectra of CS and PEO powders showed the semi crystalline nature of these polymers by the presence of two peaks at $2 \theta$ $=9.54^{\circ}$ and $19.98^{\circ}$, and two main peaks at $19.02^{\circ}$ and $23.14^{\circ}$, respectively [28,32]. In XRD pattern of CS/PEO nanofibers, the presence of PEO related peaks at $2 \theta=19.46^{\circ}$ and $23.54^{\circ}$ was observed, demonstrating that PEO crystalline structure was maintained in the nanofibers form. The diffraction pattern of CNC powder revealed three peaks at $2 \theta$ $=15.12^{\circ}, 16.45^{\circ}$ and $22.64^{\circ}$, which corresponds to crystalline cellulose I [33,34]. In CS/PEO/CNC nanofibers diffractograms, it was possible to observe the appearance of new CNC-related peaks, confirming the presence of crystalline CNC on nanofibers, although these results only start to be visible with the incorporation of $0.5 \%$ CNC. Moreover, as the CNC concentration increased there was an increase in CNC intensity peaks. For instance, with $2 \%$ CNC, the XRD spectrum clearly showed three peaks related with $\mathrm{CNC}$ at $2 \theta=15.36^{\circ}, 16.51^{\circ}$ and $22.78^{\circ}$, revealing its high crystallinity.

Therefore, all these results confirm the successful incorporation of CNC into CS/PEO nanofibers.

\subsection{WVTR and WCA}

Maintaining an ideal moist environment at the wound site is essential to promote cellular granulation and epithelization. Therefore, the evaluation of the WVTR parameter, which indicates the amount of water vapor that is transmitted through a substance, is crucial for this type of applications. Higher WVTR values are associated with a fast-wound 

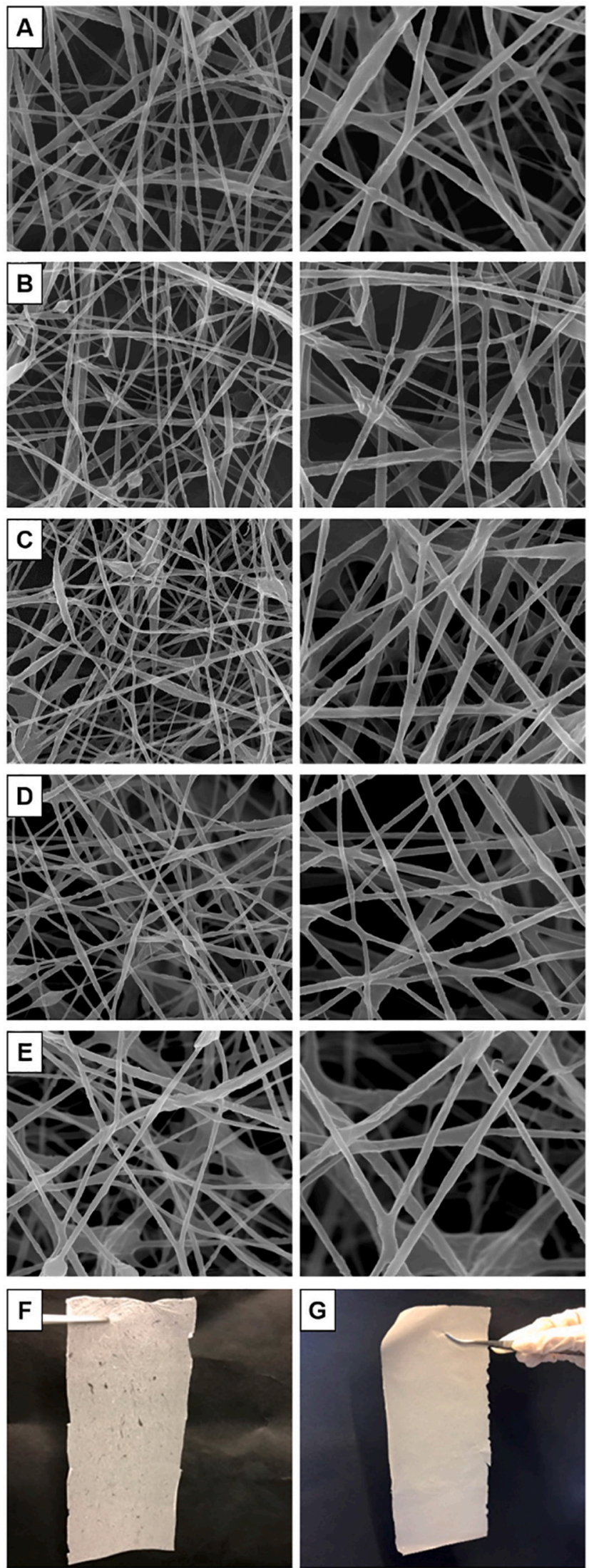
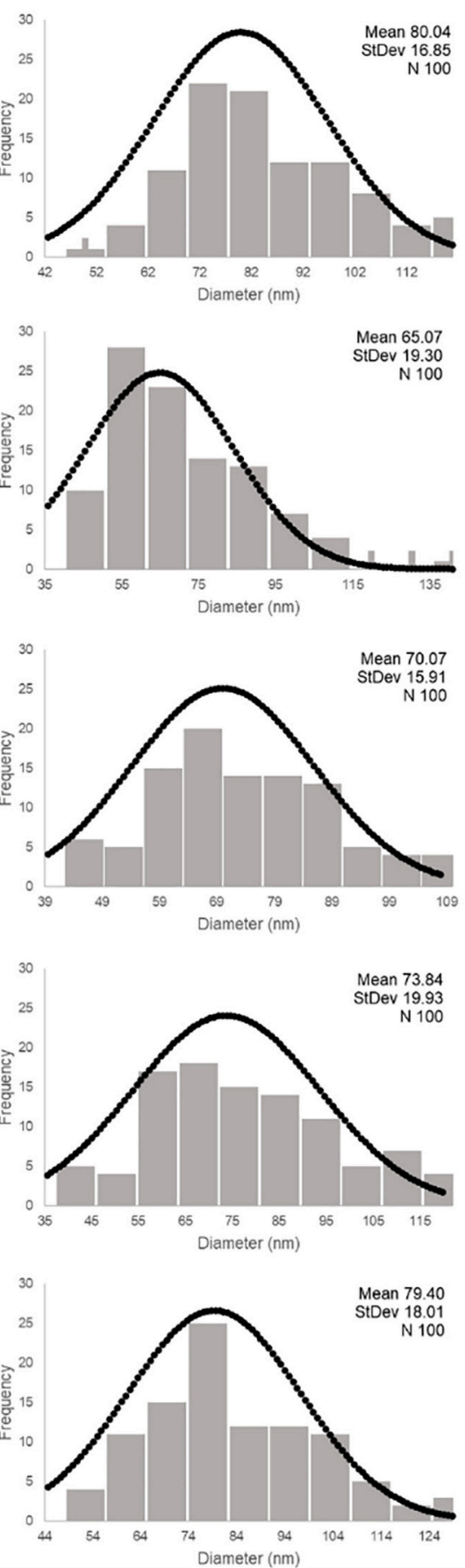

Fig. 1. FESEM images of CS/PEO nanofibers with different CNC concentrations: 0 (A), 0.1 (B), 0.5 (C), 1 (D) and 2 (E) $\%(w / v)$ and their respective diameter distribution histograms. The FESEM images were obtained using different magnifications, from left to right: $50000 \times(2 \mu \mathrm{m})$ and $100,000 \times(1 \mu \mathrm{m})$. Membranes of CS/ PEO nanofibers produced by electrospinning with $0(\mathrm{~F})$ and $1(\mathrm{G}) \%(\mathrm{w} / \mathrm{v}) \mathrm{CNC}$ (detached from aluminium foil). 

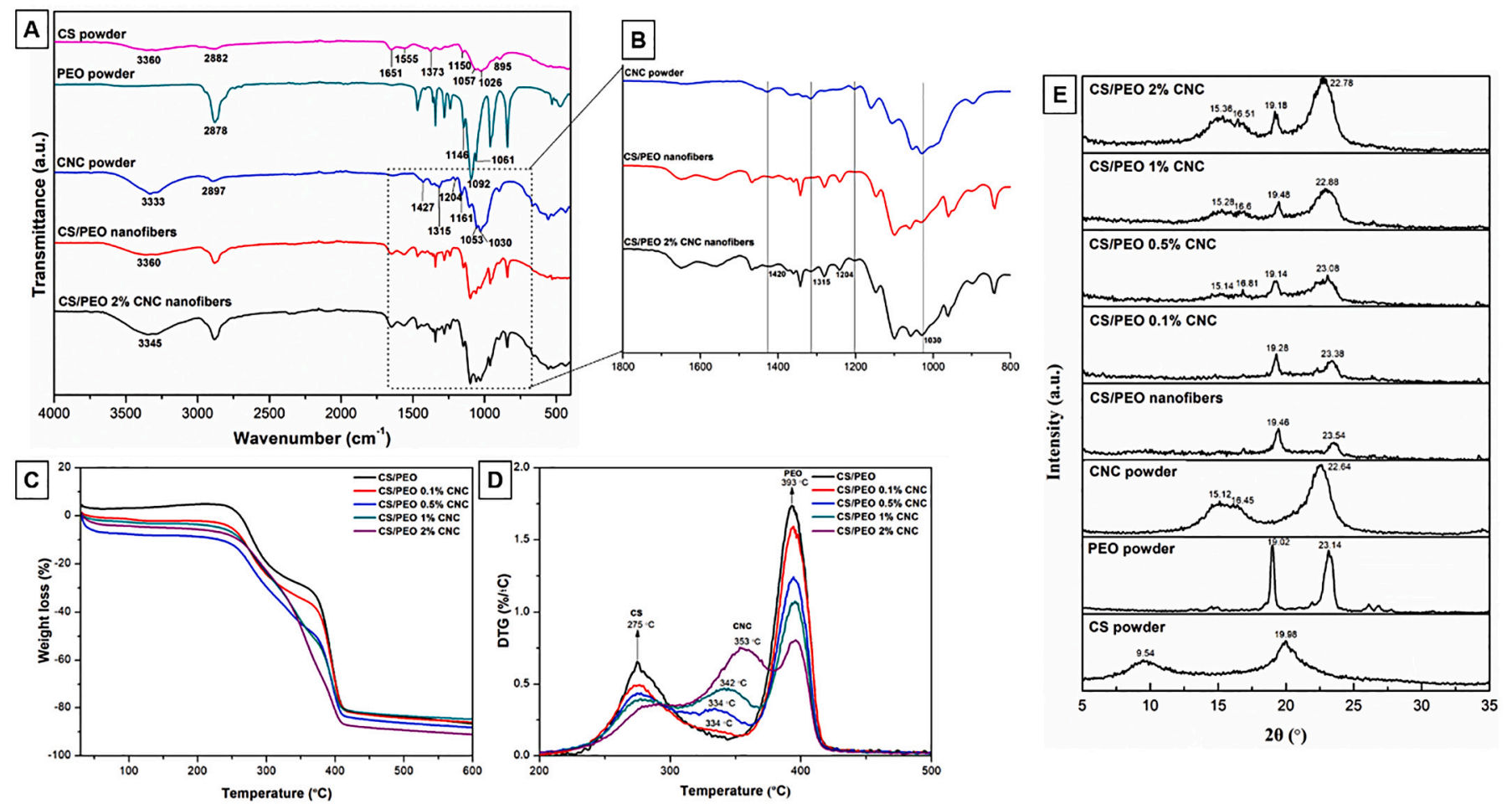

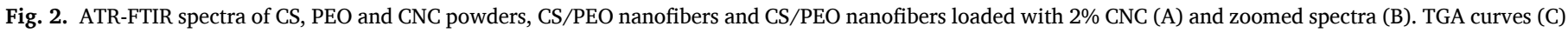

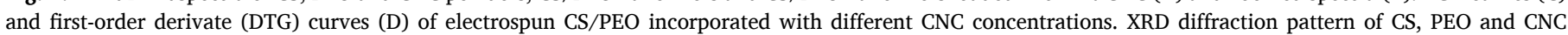
powders, CS/PEO nanofibers with different CNC concentrations $(0,0.1,0.5,1$ and 2\%(w/v)) (E).

dehydration, which can adversely decrease the body temperature and increase metabolism. In the opposite, extremely low WVTR values are correlated with exudate accumulation, inhibition of healing, and increased risk of infection [35]. According to Lamke et al., the WVTR for normal skin is $204 \pm 12 \mathrm{~g} / \mathrm{m}^{2} /$ day, while in injured skin this value can range from $278 \pm 26 \mathrm{~g} / \mathrm{m}^{2} /$ day and $5138 \pm 202 \mathrm{~g} / \mathrm{m}^{2} /$ day for first degree burns and granulating wounds, respectively [36]. The obtained WVTR values for CS/PEO and CS/PEO/2\%CNC nanofibers were $940 \pm 24 \mathrm{~g} /$ $\mathrm{m}^{2} /$ day and $1028 \pm 15 \mathrm{~g} / \mathrm{m}^{2} /$ day, respectively. The results indicate that nanofibers membranes are more suitable for moderate exuding wounds. However, it can be seen an improvement in WVTR values with the incorporation of $\mathrm{CNC}$, suggesting that the water vapor permeability directly increases with the CNC concentration.

The surface hydrophilic character also plays an important role in wound dressing applications. In this way, the WCA of the developed membranes was measured, reaching $51.4^{\circ} \pm 0.5$ and $82^{\circ} \pm 0.8$ for CS/ $\mathrm{PEO}$ and CS/PEO/CNC, respectively. These results confirmed the surface hydrophilicity of these membranes $\left(<90^{\circ}\right)$, which is a very important feature because the system capacity to absorb water will be directly related with the capacity to absorb wound exudates, allowing to keep an ideal environment for the wound healing. In addition, it is known that the deposition of proteins and adhesion factors, namely bacterial adhesion factors, is influenced by the characteristics of polymeric surfaces, occurring more readily on hydrophobic surfaces, which promote bacterial colonization. Therefore, the hydrophilic nature of the CS/PEO nanofibers with or without CNC might be favorable in deterring bacterial attachment [37].

\subsection{Characterization of CS/PEO/CNC nanofibers with acacia natural extract}

The incorporation of bioactive agents into the CS/PEO nanofibers can add new properties to nanofibers, including antimicrobial and antiinflammatory activities. These properties are essential for preventing and treating infections commonly present in wounds. Acacia natural extract has exceptional properties, namely anti-inflammatory, antibacterial and antifungal, which are very interesting for wound care applications [16]. In this way, the acacia extract was incorporated into the $\mathrm{CS} / \mathrm{PEO} / 1 \% \mathrm{CNC}$ system, since these nanofibers presented greater morphology and more uniform diameter distribution, as previously demonstrated in Fig. 1. The morphology of CS/PEO/1\%CNC/Acacia nanofibers and the respective diameter distribution histogram are shown in Fig. 3.

The incorporation of acacia natural extract did not affect the nanofibers mat structure, allowing the development of uniform and defectfree nanofibers with diameters around $83 \mathrm{~nm}$. Moreover, it was also possible the easy detachment of the nanofiber membrane from the aluminium foil used in the fibers collection.

\subsection{Antibacterial and antifungal properties of CS/PEO/CNC/Acacia nanofibers}

The antibacterial and antifungal properties of the CS/PEO, CS/PEO/ $1 \% \mathrm{CNC}, \mathrm{CS} / \mathrm{PEO} / 2 \% \mathrm{CNC}$ and $\mathrm{CS} / \mathrm{PEO} / 1 \% \mathrm{CNC} /$ Acacia nanofibers were evaluated against six different bacteria and fungi, and the respectively MIC, MBC and MFC values, expressed in $\mathrm{mg} / \mathrm{mL}$, are represented in the Table 3.

Through MIC, MBC and MFC values, it was possible to observe that all the analysed systems showed antibacterial and antifungal activity against both bacteria and fungi, however with different responses for each evaluated microorganism.

CS/PEO nanofibers already presented good antibacterial effect against Gram-positive and Gram-negative bacteria, showing low MIC (from 2 to $4 \mathrm{mg} / \mathrm{mL}$ ) and MBC (from 2 to $8 \mathrm{mg} / \mathrm{mL}$ ) values (Table $3 \mathrm{~A} 1$ ), being the highest effect observed for $B$. cereus, with MIC and MBC values of $2 \mathrm{mg} / \mathrm{mL}$. These nanofibers also presented antifungal activity against all the evaluated fungi, with MICs ranging from 0.5 to $4 \mathrm{mg} / \mathrm{mL}$ and MFCs from 0.5 to $8 \mathrm{mg} / \mathrm{mL}$, showing higher efficacy for the 

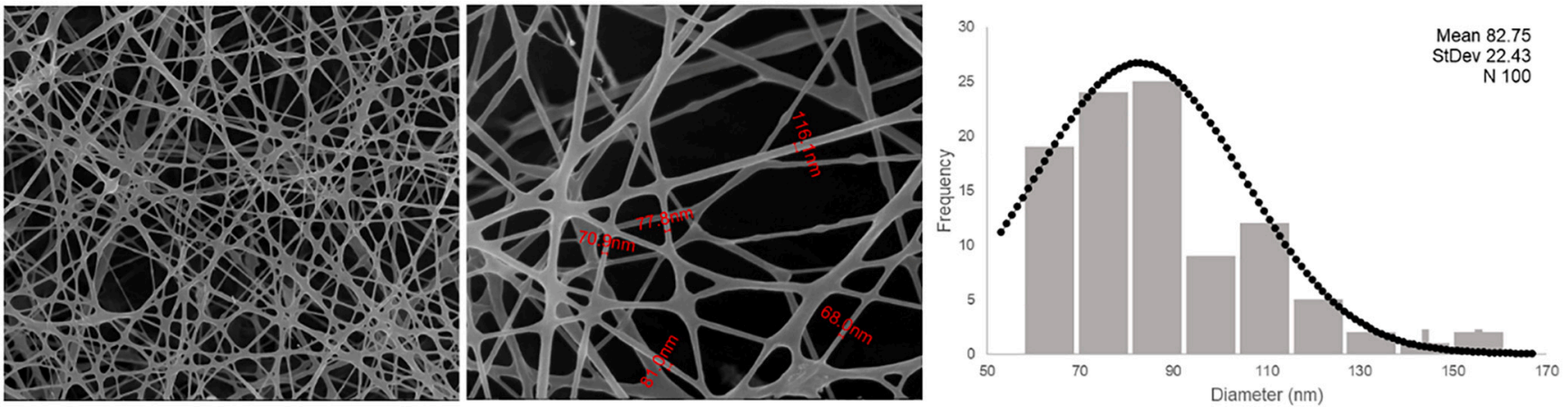

Fig. 3. FESEM images of CS/PEO/1\%CNC nanofibers incorporated with $6 \mathrm{mg} / \mathrm{mL}$ of acacia extract and diameter distribution histogram. The FESEM images were obtained using different magnifications, from left to right: $20000 \times(5 \mu \mathrm{m})$ and $50,000 \times(2 \mu \mathrm{m})$.

Table 3

Antibacterial (A) and antifungal (B) activity of the different developed CS/PEO membranes produced by electrospinning. 1) CS/PEO; 2) CS/PEO/1\%CNC; 3) CS/PEO/ $2 \% \mathrm{CNC}$; 4) CS/PEO/1\%CNC/Acacia.

\begin{tabular}{|c|c|c|c|c|c|c|c|}
\hline \multicolumn{8}{|c|}{ A - Antibacterial activity } \\
\hline $\begin{array}{l}\text { Samples } \\
\downarrow\end{array}$ & $\mathrm{MO} \rightarrow$ & S. aureus & B. cereus & L. monocytogenes & E. coli & E. cloacae & S. Typhimurium \\
\hline \multirow[t]{2}{*}{1} & MIC & 4.00 & 2.00 & 4.00 & 4.00 & 4.00 & 4.00 \\
\hline & MBC & 8.00 & 2.00 & 4.00 & 4.00 & 4.00 & 8.00 \\
\hline \multirow[t]{2}{*}{2} & MIC & 8.00 & 2.00 & 4.00 & 4.00 & 4.00 & 8.00 \\
\hline & MBC & 8.00 & 4.00 & 8.00 & 4.00 & 8.00 & 16.00 \\
\hline \multirow[t]{2}{*}{3} & MIC & 8.00 & 8.00 & 4.00 & 8.00 & 4.00 & 8.00 \\
\hline & MBC & 16.00 & 8.00 & 8.00 & 8.00 & 8.00 & 8.00 \\
\hline \multirow[t]{2}{*}{4} & MIC & 8.00 & 8.00 & 8.00 & 8.00 & 8.00 & 8.00 \\
\hline & MBC & 8.00 & 8.00 & 8.00 & 8.00 & 8.00 & 8.00 \\
\hline \multirow[t]{2}{*}{ Ampicillin } & MIC & 0.012 & 0.10 & 0.40 & 0.40 & 0.006 & 0.75 \\
\hline & MBC & 0.025 & 0.15 & 0.50 & 0.50 & 0.012 & 1.20 \\
\hline \multicolumn{8}{|c|}{ B - Antifungal activity } \\
\hline $\begin{array}{c}\text { Sample } \\
\downarrow\end{array}$ & $\mathrm{MO} \rightarrow$ & A. fumigatus & A. niger & A. versicolor & P. funiculosum & P.aurantiogriseum & T. viride \\
\hline \multirow[t]{2}{*}{1} & MIC & 4.00 & 4.00 & 2.00 & 0.50 & 1.00 & 2.00 \\
\hline & MFC & 4.00 & 8.00 & 2.00 & 0.50 & 1.00 & 2.00 \\
\hline \multirow[t]{2}{*}{2} & MIC & 2.00 & 2.00 & 1.00 & 0.50 & 1.00 & 2.00 \\
\hline & MFC & 2.00 & 4.00 & 2.00 & 1.00 & 1.00 & 4.00 \\
\hline \multirow[t]{2}{*}{3} & MIC & 4.00 & 4.00 & 1.00 & 0.50 & 0.50 & 2.00 \\
\hline & MFC & 4.00 & 4.00 & 2.00 & 1.00 & 0.50 & 2.00 \\
\hline \multirow[t]{2}{*}{4} & MIC & 2.00 & 4.00 & 1.00 & 1.00 & 1.00 & 4.00 \\
\hline & MFC & 2.00 & 4.00 & 1.00 & 2.00 & 1.00 & 4.00 \\
\hline \multirow[t]{2}{*}{ Ketoconazol } & MIC & 0.20 & 0.20 & 0.20 & 0.20 & 0.20 & 0.20 \\
\hline & MFC & 0.50 & 0.50 & 0.50 & 0.50 & 0.50 & 0.30 \\
\hline
\end{tabular}

$P$. funiculosum and lower efficiency against $A$. fumigatus and A. niger (Table 3B1). These results can be explained by the intrinsic antimicrobial properties of CS against a wide range of bacteria and fungi. Although the exact mechanism of action of CS against microorganisms is not fully understood, the main generally accepted are the electrostatic interactions between the positively charged surface of chitosan (protonated amino groups) and the negatively charged microbial cell membrane/cell wall, which affects the cell permeability, causing the leakage of intracellular material, the ability of CS to interact with microbial DNA, which will disturb the protein synthesis and the excellent chelating capacity of CS towards different metal ions [6]. Moreover, several studies already reported the antibacterial effect of chitosanbased nanofibers [31,32,38].

With the incorporation of $1 \%(w / v)$ CNC (Table 3A2), only slight changes were observed in the inhibition of bacterial growth, including an increase of MIC values from 4 to $8 \mathrm{mg} / \mathrm{mL}$ for $S$. aureus and $S$. Typhimurium. Nevertheless, with higher CNC concentrations (Table 3A3), a decrease in the antibacterial effect against $S$. aureus, $B$. cereus, $E$. coli and $S$. Typhimurium was observed. On the other hand, the incorporation of CNC (Table 3B2) promoted an enhancement in the antifungal activity for certain fungi. In fact, using $1 \%(\mathrm{w} / \mathrm{v}) \mathrm{CNC}$ a decrease in both MIC and MFC values was detected for A. fumigatus and $A$. niger, while with $2 \%(\mathrm{w} / \mathrm{v}) \mathrm{CNC}$ a decrease in MIC was observed for $A$. versicolor and $P$. aurantiogriseum and a decrease in MFC values was detected for $A$. niger and $P$. aurantiogriseum. Although it has been described that CNC alone didn't present antimicrobial effect, Amirabad et al. reported that CNC could improve the antifungal activity of CS nanofibers, namely for $A$. niger, demonstrating a synergetic effect with the combination of these materials. This finding could be due to the effect of CNC on immobilization and orientation of the CS nanofibers or could be the result of well dispersed and stabilized CS nanofibers by CNC, causing a high connection of the CS nanofibers with the fungi [39].

Finally, the incorporation of the acacia natural extract into CS/PEO/ $1 \%$ CNC nanofibers was able to improve their bactericidal effect for $S$. Typhimurium, by the reduction of MBC values from 16 to $8 \mathrm{mg} / \mathrm{mL}$ (Table 3A4). Regarding the antifungal activity, the acacia introduction (Table 3B4) promoted an inhibition of fungal growth and an enhancement of fungicidal effect, showing lower MIC and MFC values for some micromycetes, such as A. fumigatus, A. niger and A. versicolor, in comparison with other systems (Table 3B1 and B3), which is a very relevant outcome since Aspergillus spp. is one of the main fungi responsible for infections in wounds and burns $[40,41]$. Moreover, considering the CS/ 
$\mathrm{PEO} / 1 \% \mathrm{CNC}$ system, the addition of acacia also promoted a decrease in MFC value from 2 to $1 \mathrm{mg} / \mathrm{mL}$ for $A$. versicolor fungus. Most important, these values are relatively low when compared to the positive control, which indicates that the system exhibits excellent antifungal properties. To the authors best knowledge, there is only few information regarding the mechanisms of action of acacia extracts against bacteria. According to Sadiq et al. [42], the acacia extract caused morphological damages including cell integrity and cell membrane permeability, as well as changes in cell structures and growth patterns in kill-time experiments on E. coli and Salmonella strains. Nevertheless, more studies are needed to better elucidate the antimicrobial capacity of this extract.

\subsection{Cytotoxic assay}

Cytotoxic properties of the nanofibers membranes were assessed using non-tumor primary cells (PLP2) and the results (expressed in $\mu \mathrm{g}$ / $\mathrm{mL})$ are indicated in Table 4.

Non-tumor cells from pig liver (PLP2) were used since mammalian hepatocytes still represent a mandatory step for the evaluation of toxic compounds, which produce several metabolites that can be the responsible for ultimate toxicity. Furthermore, porcine liver was chosen as an in vitro cytotoxicity model due to the similarities to human in terms of cellular and physiological functioning [43]. As a positive control, ellipticine, a compound highly toxic to cells, was used. As shown in Table 4, this compound could inhibit $50 \%$ of the cell growth with a concentration of only $2.3 \pm 0.09 \mu \mathrm{g} / \mathrm{mL}$. Despite the high cytotoxicity of positive control, none of the evaluated nanofibers showed cytotoxicity for this cell line, revealing $\mathrm{GI}_{50}$ values higher than $400 \mu \mathrm{g} / \mathrm{mL}$ [44]. These results are very important for wound dressing applications since the developed nanofibers could not present cytotoxicity when in direct contact with skin.

\subsection{Acacia release profile}

The acacia release profile from $\mathrm{CS} / \mathrm{PEO} / 1 \% \mathrm{CNC} /$ Acacia nanofibers was monitored by UV-Vis spectroscopy for $24 \mathrm{~h}$ at different time points. The spectra correspondent to the time zero was measured immediately after the nanofiber membrane was placed in contact with the PECF solution, thus coinciding with the blank spectrum obtained. The absorption spectrum of the acacia in PEFC solution is represented in Fig. 4A and the spectra obtained from the acacia release from nanofibers over the time is shown in Fig. 4B.

Acacia are mainly composed by two types of phenolic compounds, flavonoids and tannins [16]. The absorption spectrum of acacia extract, Fig. 4A, revealed the presence of two absorption bands. The first one, with lower intensity at $278 \mathrm{~nm}$, corresponds to tannin compounds, while the second band, at $320 \mathrm{~nm}$ was more pronounced and is related to the flavonoids compounds $[45,46]$.

Regarding the Fig. 4B, after $5 \mathrm{~min}$, the appearance of acacia characteristic bands at 273 and $324 \mathrm{~nm}$ was very clear, which indicates an instantaneously release of acacia to the solution. An increase in intensity

\section{Table 4}

Cytotoxic activity of different developed CS/PEO membranes produced by electrospinning. 1) CS/ PEO; 2) CS/PEO/1\%CNC; 3) CS/PEO/2\%CNC; 4) $\mathrm{CS} / \mathrm{PEO} / 1 \% \mathrm{CNC} /$ Acacia. The results are expressed in $\mathrm{GI}_{50}$ values $(\mu \mathrm{g} / \mathrm{mL})$, e. g., minimal inhibitory concentration capable to inhibit $50 \%$ of the cell growth.

\begin{tabular}{ll}
\hline Samples & PLP2 \\
\hline 1 & $>400$ \\
2 & $>400$ \\
3 & $>400$ \\
4 & $>400$ \\
Ellipticine & $2.3 \pm 0.09$ \\
\hline
\end{tabular}

of the acacia absorption bands was observed between $5 \mathrm{~min}$ and $2 \mathrm{~h}$, which suggests a higher concentration of the extract in the solution and, consequently, demonstrates a gradual release of the extract over the time. After $2 \mathrm{~h}$, a new band around $250 \mathrm{~nm}$ appeared and a shift of the band around $320 \mathrm{~nm}$ to higher wavelengths was also observed. The appearance of these bands may be due to CS, one of the main constituents of the nanofiber membrane. In fact, CS has two characteristic absorption bands at 260 and $350 \mathrm{~nm}$. The presence of acacia in the solution became more pronounced after $5 \mathrm{~h}$ with the increase in intensity of the band at $273 \mathrm{~nm}$. Additionally, it was possible to identify the acacia characteristic bands for $24 \mathrm{~h}$, suggesting a continuous release of the extract at least over a day. Therefore, these results confirm the successful gradual release of the acacia natural extract from the membrane to the solution, suggesting its prolonged action, which is essential not only to accelerate the wound healing process, but also to reduce the frequency of the dressing's replacement, thereby showing the great potential of this system to be used as skin local drug delivery system.

\section{Conclusions}

In this work, bio-based nanofibers were successful developed by the electrospinning technique using biodegradable materials such as CS, $\mathrm{PEO}, \mathrm{CNC}$ and acacia. Defect-free CS/PEO nanofibers were obtained using $2 \%(w / v)$ of CS and PEO in $50 \%(v / v)$ acetic acid aqueous solution combining $29 \mathrm{kV}$ of voltage, $170 \mathrm{~mm}$ of distance between needle and collector and $4 \mathrm{~mL} / \mathrm{h}$ of flow rate and using rotating cylinder collector. These parameters resulted in the development of CS/PEO nanofibers with uniform morphology and average diameters of $80 \mathrm{~nm}$.

Several CNC concentrations $(0.1,0.5,1$ and $2 \%(\mathrm{w} / \mathrm{v}))$ were incorporated into the CS/PEO optimized solution, resulting in uniform nanofibers. The CNC incorporation led to the development of more resistant and less brittle nanofibers with fewer defects. Moreover, a more uniform diameter distribution was observed accompanied with the reduction in nanofibers' diameters. Furthermore, the introduction of CNC promoted an improvement of CS/PEO nanofiber's thermal stability as well as an enhancement of WVTR values, which is essential for the treatment of injured skin.

Finally, the incorporation of acacia extract resulted in uniform and defect-free nanofibers with diameters of $83 \mathrm{~nm}$, and the antibacterial and antifungal properties of the developed nanofibers were evaluated. Besides CS/PEO and CS/PEO/CNC nanofibers presented antimicrobial activity, nanofibers incorporated with acacia also showed excellent antibacterial activity against several Gram-positive and Gram-negative bacteria while improved antifungal effect against $A$. versicolor fungus. Additionally, none of the evaluated systems (CS/PEO, CS/PEO/CNC and $\mathrm{CS} / \mathrm{PEO} / \mathrm{CNC} /$ Acacia) showed cytotoxic activity in PLP2 non-tumor cells, suggesting their biocompatibility, which is extremely important for skin applications. Lastly, a continuous release of the extract was observed for $24 \mathrm{~h}$, confirming the prolonged effect of the nanofiber's membranes containing the natural extract at least over a day.

Hence, the developed antimicrobial nanofibers based on biodegradable polymers, CS and PEO, natural-based reinforcing agents, CNC, and plant-based antimicrobial agents, acacia, demonstrated to be a very promising and eco-friendly combination to be used as skin localized agents for wound dressing applications.

\section{Funding}

The authors are thankful to TSSiPRO project, operation code NORTE01-0145-FEDER-000015. The authors are also grateful to FCT, Portugal for financial support through national funds FCT/MCTES to CIMO (UIDB/00690/2020) and to 2C2T (UID/CTM/00264/2019). D. P. Ferreira thank the national funding by FCT through the individual scientific employment program-contract (CEECIND/02803/2017), S. M. Costa thank the FCT PhD Scholarship (SFRH/BD/147517/2019), and L. Barros and R. Calhelha thank the institutional scientific employment 

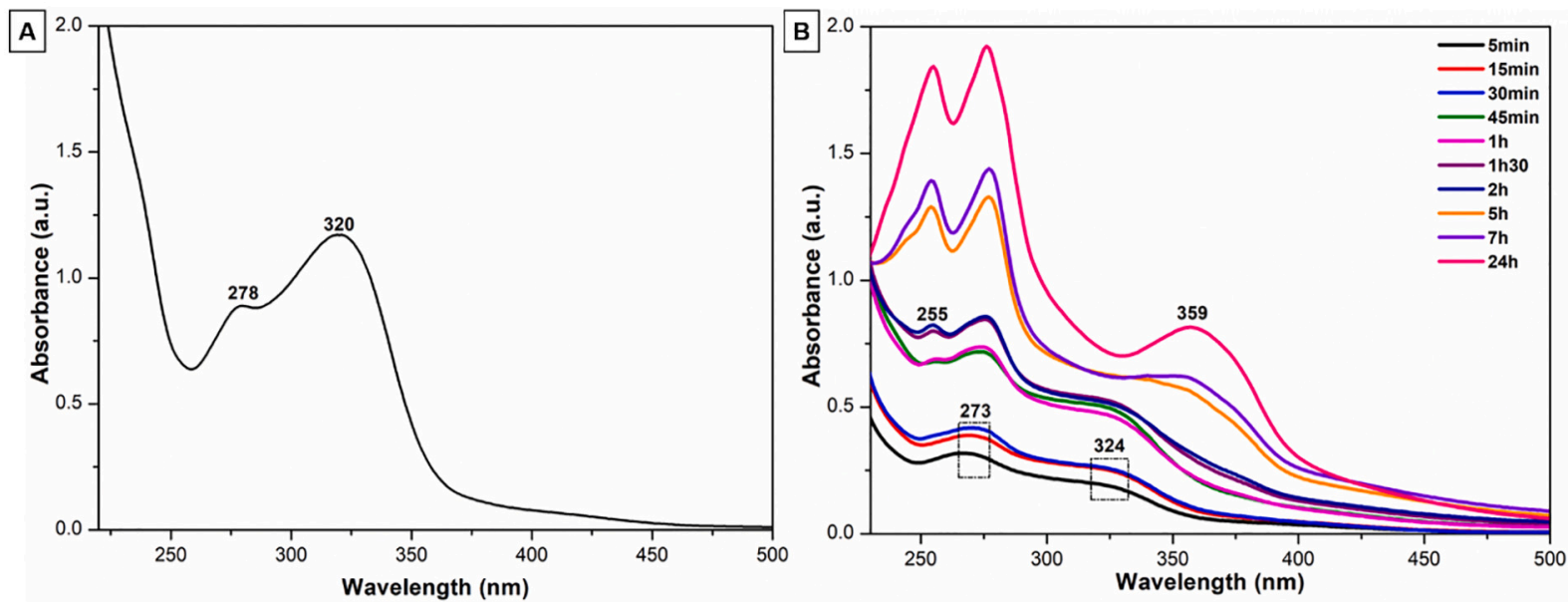

Fig. 4. Absorption spectra of the PECF solution containing acacia (A) and the release profile of the natural acacia extract from the nanofiber membrane to the solution for a period of $24 \mathrm{~h} \mathrm{(B)}$.

program-contract. This work has been supported by the Ministry of Education, Science and Technological Development of Republic of Serbia (451-03-68/2020-14/200007).

\section{Data availability}

The raw/processed data required to reproduce these findings cannot be shared at this time as the data also forms part of an ongoing study.

\section{Declaration of Competing Interest}

The authors declare that they have no known competing financial interests or personal relationships that could have appeared to influence the work reported in this paper.

\section{References}

[1] D. Chouhan, N. Dey, N. Bhardwaj, B.B. Mandal, Emerging and innovative approaches for wound healing and skin regeneration: current status and advances, Biomaterials 216 (2019), 119267, https://doi.org/10.1016/j. biomaterials.2019.119267.

[2] S.P. Miguel, D.R. Figueira, D. Simões, M.P. Ribeiro, P. Coutinho, P. Ferreira, I. J. Correia, Electrospun polymeric nanofibres as wound dressings: a review, Colloids Surf. B: Biointerfaces 169 (2018) 60-71, https://doi.org/10.1016/j. colsurfb.2018.05.011.

[3] A. Memic, T. Abudula, H.S. Mohammed, K. Joshi Navare, T. Colombani, S. A. Bencherif, Latest progress in electrospun nanofibers for wound healing applications, ACS Appl. Bio Mater. 2 (2019) 952-969, https://doi.org/10.1021/ acsabm. 8b00637.

[4] S. Homaeigohar, A.R. Boccaccini, Antibacterial biohybrid nanofibers for wound dressings, Acta Biomater. 107 (2020) 25-49, https://doi.org/10.1016/j. actbio.2020.02.022.

[5] M.A. Teixeira, M.C. Paiva, M.T.P. Amorim, A.H.P. Felgueiras, Electrospun nanocomposites containing cellulose and its derivatives modified with specialized biomolecules for an enhanced wound healing, Nanomater. (Basel, Switzerland) 10 (2020) 557, https://doi.org/10.3390/nano10030557.

[6] M.A. Matica, F.L. Aachmann, A. Tøndervik, H. Sletta, V. Ostafe, Chitosan as a wound dressing starting material: antimicrobial properties and mode of action, Int. J. Mol. Sci. 20 (2019) 5889, https://doi.org/10.3390/ijms20235889.

[7] N.P. Rijal, U. Adhikari, N. Bhattarai, 9 - production of electrospun chitosan for biomedical applications, in: J.A. Jennings, J.D. Bumgardner (Eds.), Chitosan Based Biomaterials, Woodhead Publishing, 2017, pp. 211-237.

[8] N. Amiri, S. Ajami, A. Shahroodi, N. Jannatabadi, S. Amiri Darban, B.S. Fazly Bazzaz, E. Pishavar, F. Kalalinia, J. Movaffagh, Teicoplanin-loaded chitosan-PEO nanofibers for local antibiotic delivery and wound healing, Int. J. Biol. Macromol. 162 (2020) 645-656, https://doi.org/10.1016/j.ijbiomac.2020.06.195.

[9] M. Pakravan, M.-C. Heuzey, A. Ajji, A fundamental study of chitosan/PEO electrospinning, Polymer (Guildf). 52 (2011) 4813-4824, https://doi.org/ 10.1016/j.polymer.2011.08.034.

[10] D. Missiani Ridolfi, A. Lemes, S. Oliveira, G. Justo, M. Palladino, N. Duran, Electrospun poly(ethylene oxide)/chitosan nanofibers with cellulose nanocrystals as support for cell culture of 3T3 fibroblasts, Cellulose 24 (2017) 1-13, https://doi. org/10.1007/s10570-017-1362-2
[11] C. Zhou, R. Chu, R. Wu, Q. Wu, Electrospun polyethylene oxide/cellulose nanocrystal composite nanofibrous mats with homogeneous and heterogeneous microstructures, Biomacromolecules 12 (2011) 2617-2625, https://doi.org/ 10.1021/bm200401p.

[12] S. Ghayempour, M. Montazer, M. Mahmoudi Rad, Encapsulation of aloe Vera extract into natural Tragacanth gum as a novel green wound healing product, Int. J. Biol. Macromol. 93 (2016) 344-349, https://doi.org/10.1016/j. ijbiomac.2016.08.076.

[13] A.-M. Croitoru, D. Ficai, A. Ficai, N. Mihailescu, E. Andronescu, C.F. Turculet, Nanostructured fibers containing natural or synthetic bioactive compounds in wound dressing applications, Mater. (Basel, Switzerland) 13 (2020) 2407, https:// doi.org/10.3390/ma13102407.

[14] A.K. Lakhera, V. Kumar, Monosaccharide composition of acidic gum exudates from Indian Acacia tortilis ssp. raddiana (Savi) Brenan, Int. J. Biol. Macromol. 94 (2017) 45-50, https://doi.org/10.1016/j.ijbiomac.2016.09.097.

[15] S. Musallam, A. Alawi, M.A. Hossain, A.A. Abusham, Antimicrobial and cytotoxic comparative study of different extracts of Omani and Sudanese gum acacia, BeniSuef Univ. J. Basic Appl. Sci. 7 (2018) 22-26, https://doi.org/10.1016/j. bjbas.2017.10.007.

[16] B.E.C. Ziani, M. Carocho, R.M.V. Abreu, K. Bachari, M.J. Alves, R.C. Calhelha, O. Talhi, L. Barros, I.C.F.R. Ferreira, Phenolic profiling, biological activities and in silico studies of Acacia tortilis (Forssk.) Hayne ssp. raddiana extracts, Food Biosci. 36 (2020), 100616, https://doi.org/10.1016/j.fbio.2020.100616.

[17] T. Tsukatani, H. Suenaga, M. Shiga, K. Noguchi, M. Ishiyama, T. Ezoe, K. Matsumoto, Comparison of the WST- 8 colorimetric method and the CLSI broth microdilution method for susceptibility testing against drug-resistant bacteria, J. Microbiol. Methods 90 (2012) 160-166, https://doi.org/10.1016/j. mimet.2012.05.001.

[18] K. Bush, M.N. Dudley, D.W. Hecht, Methods for Dilution Antimicrobial Susceptibility Tests for Bacteria That Grow Aerobically; Approved Standard, eighth ed., Clin. Lab. Stand. Inst, 2009.

[19] R.K. Daouk, S.M. Dagher, E.J. Sattout, Antifungal activity of the essential oil of Origanum syriacum L, J. Food Prot. 58 (1995) 1147-1149, https://doi.org/ 10.4315/0362-028X-58.10.1147.

[20] A.N.A. Espinel-ingroff, Comparison of the E-test with the NCCLS M38-P method for antifungal susceptibility testing of common and emerging pathogenic filamentous fungi, J. Clin. Microbiol. 39 (2001) 1360-1367, https://doi.org/10.1128/ JCM.39.4.1360.

[21] R.M.V. Abreu, I.C.F.R. Ferreira, R.C. Calhelha, R.T. Lima, M.H. Vasconcelos, F. Adega, R. Chaves, M.-J.R.P. Queiroz, Anti-hepatocellular carcinoma activity using human HepG2 cells and hepatotoxicity of 6-substituted methyl 3-aminothieno[3,2-b]pyridine-2-carboxylate derivatives: in vitro evaluation, cell cycle analysis and QSAR studies, Eur. J. Med. Chem. 46 (2011) 5800-5806, https://doi. org/10.1016/j.ejmech.2011.09.029.

[22] V. Vichai, K. Kirtikara, Sulforhodamine B colorimetric assay for cytotoxicity screening, Nat. Protoc. 1 (2014) 1112-1116, https://doi.org/10.1038/ nprot.2006.179.

[23] D.P. Ferreira, D.S. Conceicao, R.C. Calhelha, T. Sousa, R. Socoteanu, I.C.F. R. Ferreira, L.F. Vieira Ferreira, Porphyrin dye into biopolymeric chitosan films for localized photodynamic therapy of cancer, Carbohydr. Polym. 151 (2016) 160-171, https://doi.org/10.1016/j.carbpol.2016.05.060.

[24] S. Fathollahipour, A.A. Mehrizi, A. Ghaee, M. Koosha, Electrospinning of PVA/ chitosan nanocomposite nanofibers containing gelatin nanoparticles as a dual drug delivery system, J. Biomed. Mater. Res. Part A 103 (2015), https://doi.org/ 10.1002/jbm.a.35529.

[25] D. Wang, W. Cheng, Q. Wang, J. Zang, Y. Zhang, G. Han, Preparation of electrospun chitosan/poly(ethylene oxide) composite nanofibers reinforced with cellulose nanocrystals: structure, morphology, and mechanical behavior, Compos. 
Sci. Technol. 182 (2019), 107774, https://doi.org/10.1016/j. compscitech.2019.107774.

[26] D. Wang, W. Cheng, Y. Yue, L. Xuan, X. Ni, G. Han, Electrospun cellulose nanocrystals/chitosan/polyvinyl alcohol nanofibrous films and their exploration to metal ions adsorption, Polymers (Basel). 10 (2018) 1046, https://doi.org/ 10.3390/polym10101046.

[27] M.S. Peresin, Y. Habibi, J.O. Zoppe, J.J. Pawlak, O.J. Rojas, Nanofiber composites of polyvinyl alcohol and cellulose nanocrystals: manufacture and characterization, Biomacromolecules 11 (2010) 674-681, https://doi.org/10.1021/bm901254n.

[28] M. Pakravan, M.-C. Heuzey, A. Ajji, Core-shell structured PEO-chitosan nanofibers by coaxial electrospinning, Biomacromolecules 13 (2012) 412-421, https://doi. org/10.1021/bm201444v.

[29] H. Kargarzadeh, R. M. Sheltami, I. Ahmad, I. Abdullah, A. Dufresne, Cellulose nanocrystal: a promising toughening agent for unsaturated polyester nanocomposite, Polymer (Guildf). 56 (2015) 346-357, https://doi.org/10.1016/j. polymer.2014.11.054.

[30] M. Mujtaba, A.M. Salaberria, M.A. Andres, M. Kaya, A. Gunyakti, J. Labidi, Utilization of flax (Linum usitatissimum) cellulose nanocrystals as reinforcing material for chitosan films, Int. J. Biol. Macromol. 104 (2017) 944-952, https:// doi.org/10.1016/j.ijbiomac.2017.06.127.

[31] S. Abid, T. Hussain, A. Nazir, A. Zahir, S. Ramakrishna, M. Hameed, N. Khenoussi, Enhanced antibacterial activity of PEO-chitosan nanofibers with potential application in burn infection management, Int. J. Biol. Macromol. 135 (2019) 1222-1236, https://doi.org/10.1016/j.ijbiomac.2019.06.022.

[32] Y. Fazli, Z. Shariatinia, Controlled release of cefazolin sodium antibiotic drug from electrospun chitosan-polyethylene oxide nanofibrous Mats, Mater. Sci. Eng. C Mater. Biol. Appl. 71 (2017) 641-652, https://doi.org/10.1016/j, msec.2016.10.048.

[33] A. Hivechi, S.H. Bahrami, R.A. Siegel, Investigation of morphological, mechanical and biological properties of cellulose nanocrystal reinforced electrospun gelatin nanofibers, Int. J. Biol. Macromol. 124 (2019) 411-417, https://doi.org/10.1016/ j.ijbiomac.2018.11.214.

[34] Q.-J. Chen, L.-L. Zhou, J.-Q. Zou, X. Gao, The preparation and characterization of nanocomposite film reinforced by modified cellulose nanocrystals, Int. J. Biol. Macromol. 132 (2019) 1155-1162, https://doi.org/10.1016/j. ijbiomac.2019.04.063.

[35] R. Machado, V. Sencadas, C. Garcia-ar, C.M. Costa, J. Padr, Electrospun silkelastin-like fibre mats for tissue engineering applications, Biomed. Mater. 8 (2013), 065009, https://doi.org/10.1088/1748-6041/8/6/065009.
[36] L.-O. Lamke, S.-O. Liljedahl, Evaporative water loss from burns, grafts and donor sites, Scand. J. Plast. Reconstr. Surg. 5 (1971) 17-22, https://doi.org/10.3109/ 02844317109042932.

[37] T.T. Yuan, A. Marie, D. Foushee, M.C. Johnson, A.R. Jockheck-clark, J.M. Stahl, Development of electrospun chitosan- polyethylene oxide/fibrinogen biocomposite for potential wound healing applications, Nanoscale Res. Lett. 13 (2018) 88, https://doi.org/10.1186/s11671-018-2491-8.

[38] I. Kohsari, Z. Shariatinia, S.M. Pourmortazavi, Antibacterial electrospun chitosanpolyethylene oxide nanocomposite mats containing bioactive silver nanoparticles, Carbohydr. Polym. 140 (2016) 287-298, https://doi.org/10.1016/j. carbpol.2015.12.075.

[39] L. Mohammadi Amirabad, M. Jonoobi, N.S. Mousavi, K. Oksman, A. Kaboorani, $\mathrm{H}$. Yousefi, Improved antifungal activity and stability of chitosan nanofibers using cellulose nanocrystal on banknote papers, Carbohydr. Polym. 189 (2018) 229-237, https://doi.org/10.1016/j.carbpol.2018.02.041.

[40] M. Obradovic-Tomasev, A. Popovic, N. Vuckovic, M. Jovanovic, Mixed fungal infection (Aspergillus, Mucor, and Candida) of severe hand injury, Case Rep. Infect. Dis. 2014 (2014), 954186, https://doi.org/10.1155/2014/954186.

[41] G. Chellan, S. Shivaprakash, S. Karimassery Ramaiyar, A.K. Varma, N. Varma, M. Thekkeparambil Sukumaran, J. Rohinivilasam Vasukutty, A. Bal, H. Kumar, Spectrum and prevalence of fungi infecting deep tissues of lower-limb wounds in patients with type 2 diabetes, J. Clin. Microbiol. 48 (2010) 2097-2102, https://doi. org/10.1128/JCM.02035-09.

[42] M.B. Sadiq, J. Tarning, T.Z. Aye Cho, A.K. Anal, Antibacterial activities and possible modes of action of Acacia nilotica (L.) Del. Against multidrug-resistant Escherichia coli and Salmonella, Molecules 22 (2017) 47, https://doi.org/ 10.3390/molecules22010047.

[43] R.C. Calhelha, S. Falcao, M.J.R.P. Queiroz, M. Vilas-Boas, I.C.F.R. Ferreira, Cytotoxicity of Portuguese propolis: the proximity of the in vitro doses for tumor and normal cell lines, Biomed. Res. Int. 2014 (2014), 897361, https://doi.org/ 10.1155/2014/897361.

[44] S.A. Heleno, I.C.F.R. Ferreira, R.C. Calhelha, A.P. Esteves, A. Martins, M. João, R. P. Queiroz, Cytotoxicity of Coprinopsis atramentaria extract, organic acids and their synthesized methylated and glucuronate derivatives, FRIN 55 (2014) 170-175, https://doi.org/10.1016/j.foodres.2013.11.012.

[45] C. Santos, J.H.Z. dos Santos, Direct analysis of total tannins encapsulated in silica matrices by ultraviolet-visible diffuse reflectance spectroscopy, Anal. Methods 8 (2016) 3774-3779, https://doi.org/10.1039/C5AY03226A.

[46] Z. Jurasekova, J.V. Garcia-Ramos, C. Domingo, S. Sanchez-Cortes, Surfaceenhanced Raman scattering of flavonoids, J. Raman Spectrosc. 37 (2006) 1239-1241, https://doi.org/10.1002/jrs.1634. 